\title{
LA SUTURA LEGIBLE Y SUBALTERNA DE LA FICCIÓN HISTÓRICA DE LA CHILENIDAD EN DURANTE LA RECONQUISTA (1897) DE ALBERTO BLEST GANA
}

\section{Alvaro Kaempfer*}

\section{RESUMEN}

Si el periodo de la Reconquista ha sido visto por la historiografía chilena como un momento fundacional de una identidad política nacional, la narrativa de Blest Gana articula su construcción sobre una imagen de lo popular que cohesiona esta visión hegemónica. Este artículo explora la legibilidad de lo subalterno a partir de la interpretación o invención de una figura popular que ordena el recuento de la Reconquista hecho por la ficción histórica de Blest Gana.

Palabras clave: Blest Gana, Reconquista, subalternidad, etnicidad, nación.

\section{ABSTRACT}

If the Reconquest period has been seen by Chilean historiography as a foundational moment for a political national identity, Blest Gana's narrative articulates its construction over an image of the popular that lends cohesion to this hegemonic vision. This article explores the legibility of the subaltern through an interpretation or invention of a popular figure around which Blest Gana organizes an account of the Reconquest in his historical fiction.

Keywords: Blest Gana, Reconquest, subalternity, ethnicity and nation.

Recibido: 03.05.2006. Aceptado: 07.09.2006.

* Department of Latin Studies University of Richmond, Virginia, EE.UU. E-mail: akaempfe@richmond.edu 

URANTE la Reconquista (1897) de Alberto Blest Gana esboza la formación de una cultura nacional chilena a partir de la reconquista española de la Capitanía General de Chile tras el desastre de Rancagua en 1814. El triunfo realista pulverizó las fuerzas criollas y anuló la decisión de autogobierno tomada por el Cabildo de Santiago en septiembre de 1810. Asimismo, desató un proceso que culminaría con la cohesión de una comunidad a partir de la resistencia criolla a la restauración colonial y a la represión realista. Blest Gana sitúa su novela entre la derrota criolla en octubre de 1814 y la victoria sobre las tropas del rey por parte del Ejército de los Andes en febrero de 1817. Aferrado a la historiografía del periodo, el texto sugiere que esa experiencia de resistencia creó un sentido de nacionalidad cuya factura permitió consolidar la hegemonía postcolonial de las élites. Blest Gana revisa la matriz historiográfica e intenta suturar las fisuras de su armazón narrativo. Bajo esta perspectiva, me permito hurgar en las grietas del relato hegemónico nacional, al que busca reforzar Blest Gana a partir de la construcción de lo popular en base al lugar de los grupos subalternos en su diseño. Con este propósito, echo mano a una serie de reflexiones generadas por los estudios post-coloniales y subalternos.

La novela de Blest Gana acusa, según Guillermo Gotschlich, "dos tiempos históricos: el fin de la dependencia colonialista y el tránsito hacia la libertad institucional y la constitución del sentido de nacionalidad de su país" (1992: 53). Explora, así, la sociedad chilena "en un momento de transición entre el coloniaje y la independencia" (Camurati, 1974: 94). La narrativa no parece ajena al debate finisecular sobre la nación, su orden y cultura hegemónicas que revisa aquel "primer espacio" nacional, como diría Alberto Moreiras (1999: 42). Blest Gana retorna al hipotético momento de fundación nacional tras la genealogía de la articulación política y cultural de la sociedad chilena. Por su novela cruzan pueblo, aristocracia criolla, tipos arrancados del costumbrismo y personajes que oscilan entre la historia, la ficción y la historiografía, dando forma a la totalización que llevó a Arturo Torres Rioseco a sugerir que el modelo era Tosltoy (1962: 504). Esta interpretación histórica, de sello totalizador y enciclopédico de Blest Gana, subraya el episodio fundacional de una hipotética nacionalidad chilena y parece ligado a los debates sobre nación, raza y hegemonía finiseculares. Son, también secuelas del frágil orden surgido tras la revolución de 1891, el suicidio de Balmaceda y la difusa república parlamentaria que atisba Blest Gana desde Europa. Como señala Michael Rössner, "[1] a novela histórica tradicional, además de la función didáctica, creadora de identidades nacionales, tenía siempre también una función actualizante, una relación más o menos subrayada con el presente" (1999: 73). Estos fenómenos rozan el armazón general del relato.

En sus primeras páginas, la novela dice dar cuenta del "segundo acto del luctuoso drama de la reconquista española. El primero acababa de terminar 


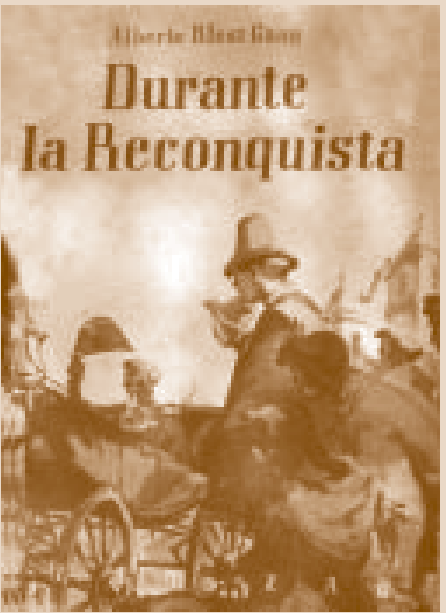

Durantela Reconquista en edición Zig-Zag de los años 50

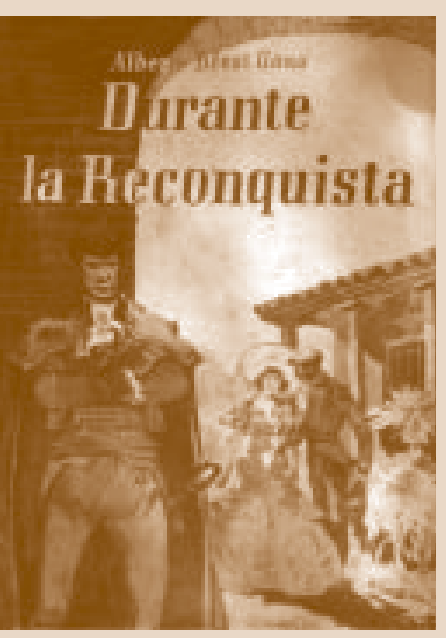

con la tremenda jornada de Rancagua" (Blest Gana, 1897: 3). La alusión al lugar de una derrota demarca el sitio de una épica cuya factura narrativa se ubica, para seguir a Hayden White, entre Scott y Ranke (1975: 163). Bernardo O'Higgins y los suyos, tras romper el acoso enemigo y huir a Mendoza, dejaron "un rastro de fuego en la imaginación de los contemporáneos y una aureola indeleble en los anales de la causa inspiradora de tan heroica temeridad” (Blest Gana, 1897:3). Sobre ese rastro y “[d]ándole ya la forma augusta de una tradición venerada, el pueblo se contaba la reciente hazaña con admiración" (Blest Gana, 1897: 3). La apertura de la novela remite tanto al episodio histórico de Rancagua como a la oralidad con que la imaginación popular forjó una épica nacional. En este cruce de relatos sitúa Blest Gana la narración y protagonismo de grupos subalternos. Por subalterno aludo, inicialmente, a segmentos sociales que se deslizan o huyen de su representación al interior del discurso que los autoriza (Beverley, 1999:101-102).

En el relato de Blest Gana, la difusa figura de la subalternidad surge a través de diversos personajes. Uno de ellos es Filiberto Cámara, cuya participación en Rancagua lleva a la novela a caracterizarlo como un "intrépido hijo del pueblo" (Blest Gana, 1897: 117). Cámara escapó a caballo siguiendo la orden dada por O'Higgins de romper el cerco realista. O'Higgins y su tropa cruzaron los Andes, se reunieron con José de San Martín en Mendoza y volvieron victoriosos casi tres años después. Esa, sin embargo, es otra historia. La de Cámara y Robles sigue a pie en las afueras de Rancagua. El caballo que montaban es alcanzado por las balas y una vez " $[\mathrm{m}]$ uerto el alazán era preciso resignarse a huir a pie" (Blest Gana 116). Luego, "asilándose en los ranchos, o escondiéndose en los potreros, habían logrado sustraerse a la vigilancia de los curiosos, o de los que por miedo a los españoles, habrían podido denunciarlos" (Blest Gana, 1897: 120). Su objetivo, tras haber cambiado "el traje militar por los vestidos de paisano, que malamente los cubrían a su Mayor y a él", era llegar a la casa patronal del fundo Los Canelos (Blest Gana, 1897: 120). Éste es propiedad de los Malsira, viejos patrones de Cámara, cuyo jefe de familia, Don Alejandro, es en la novela el prototipo del criollo aristocrático, patriota y heroico.

Camino al fundo, en la posada del Ñ ato Contreras en Talagante, mate en mano y a una orden del mayor Robles, Cámara le relata su versión del sitio de Rancagua a una audiencia de huasos que "de pie o sentados sobre el suelo, escuchaban y bebían" (Blest Gana, 1897: 107). La escena traza un "pacto de credibilidad" basado en la fiabilidad del testigo para una audiencia que simpatiza con su lugar en los hechos narrados (Sklodowska, 1996: 95). Aquí, el narrador novelesco cede su lugar a Cámara quien, como actor y testigo de lo sucedido, habla, desplazando la novela a la condición de paratexto, a la Genette, que sitúa y respalda la fuerza ilocucionaria del relato de Cámara (Genette, 1980: 274). En su testimonio, Cámara da "forma a los vívidos y frescos recuerdos de las escenas del sitio en que había sido actor" (Blest Gana 
110). El sitio aludido ya no es sólo Rancagua sino el lugar bélico, narrativo e histórico del subalterno protagonismo de Cámara en la novela. Desde allí surge una subalternidad funcional a la matriz historiográfica y narrativa de la novela, subrayado a pocas líneas de haber comenzado aquél su relato.

Cámara, advierte la narración, habla "con el lenguaje pintoresco del campamento y esa singularidad de voces y de pronunciación con que la gente del pueblo ha formado un idioma peculiar" (Blest Gana, 1897: 110). Cámara contrasta en una historia, como diría Alfonso Escudero, de caballeros con "abolengo y distinción, aunque haya pobreza", escrita por un señor santiaguino que, según Mariano Latorre, sólo vio rotos de paseo por el campo (Escudero, 1945: XXIX). El testimonio de Cámara no contraviene sino que reafirma el relato de los hechos que trazan la instalación de la hegemonía de las élites criollas, ante una audiencia que responde a un circuito oral al margen de la escritura historiográfica. La narrativa toma palco frente al storyteller que cubre un punto ciego de su relato. Cámara no es integrado por su rol en la historia sino que su protagonismo deriva de las palabras que refuerzan el discurso y la visión hegemónica puestos en juego por la novela. En consecuencia, su testimonio fija tanto los límites de su protagonismo como su étnica y lingüística otredad en tanto informante. La novela aclara, puntualmente, que el relato de Cámara, "traducido ortográficamente en la escritura sería difícil y engorroso de leerse" (Blest Gana, 1897: 110-111). Ambos deben ser corregidos para que la transcripción de su habla garantice la legibilidad de su historia y la comprensión general del texto.

Si la novela, como género, "reconoce la existencia de otros discursos y establece con ellos un diálogo", ese diálogo responde aquí a un habla cuya legibilidad, corregida y transcrita, anularía la polifonía bajtiniana (Sklodowska 1992: 93). El discurso de Cámara no triza la factura totalizadora de la novela sino que surge ligado al relato historiográfico que hace de su performance oral una matriz interpretativa y un mecanismo de inscripción de la subalternidad. El vínculo genético del testimonio de Cámara con esa oralidad "explica el proceso que culmina en lo ya sabido", para decirlo en palabras de Noé Jitrik (1986: 14). Raúl Silva Castro señaló que el diálogo intertextual de la novela habría sido con "las narraciones autorizadas por los nombres de Barros Arana y de Amunátegui, los dos principales historiadores de la Reconquista hasta esos días" (1960: 79). La referencia de Silva Castro al volumen X de la Historia General de Chile de Diego Barros Arana y a La Reconquista Española de Miguel Luis y Gregorio Víctor Amunátegui reafirmaría su mímica en el relato de Cámara. Esta mímica, en el sentido dado al término por Homi Bhabha, subraya los excesos de un habla subalterna que lo confirma en otros dominios discursivos (1994: 86). La novela le transfiere a Cámara un relato ligado a la historiografía decimonónica y su contratransferencia permite recuperar ese relato tras su enunciación popular. Cámara

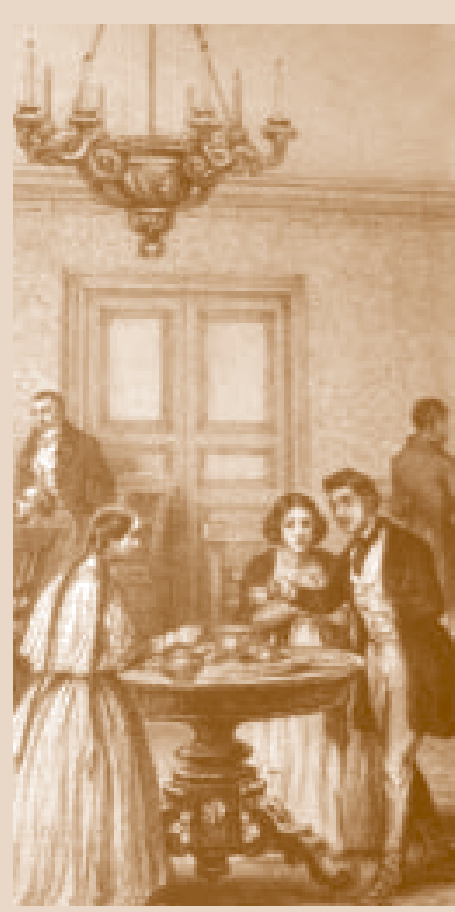

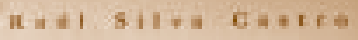

mHEST GANA Y BU NOVKLA

DURANTE LA RECONOUIST $\mathrm{A}$.

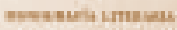

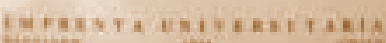
nentises 
Cámara responden a una desviación de la lengua y del discurso historiográfico que aseguran la legibilidad política de una ficción histórica.

Cámara remite al diseño de un relato hegemónico que no admite otras ni diferentes historias. Es el mutismo que, allá lejos y hace tiempo, le atribuyera al subalterno Gayatri Spivak (1994: 80). Pero no se trata de que el subalterno pueda hablar ni, como añade Sommer, de que su contraparte pueda oírlo (1999: 20). Se trata, como sostiene Judith Butler en relación con el habla imposible del subalterno al interior de los relatos que lo cooptan, del problema de su legibilidad (2000:36). El mutismo de Cámara apunta a una política de la lengua que subordina su representación, entonces, a su legibilidad en una interpretación de lo popular a fines del siglo XIX. La ilegible condición del habla de Cámara, extensiva a la gente del pueblo en la ficción de Blest Gana, define su particularidad y diferencia. Esta va unida a la que afirma que, "[a] los catorce años, el rotito, con los instintos nómades de su raza, andaba de pueblo en pueblo, rodando tierras, como él decía, trabajando si le faltaba con qué comer, pero con más frecuencia jugando a las chapitas, con vagos y rateros" (Blest Gana, 1897: 118). Tales actividades "traen frecuentemente riñas entre la gente del pueblo. En ellas había ejercitado Cámara su natural belicoso" (Blest Gana, 1897: 118). En ese boceto socio-biográfico, Cámara ejemplifica "[e]sa mezcla de conquistador hispano-arábigo y de araucano que ha formado el roto chileno" (Blest Gana, 1897: 118). Su presencia y acción en los hechos narrados responde a una matriz racial. Sin embargo, aclara la novela, "el vértigo de la sangre" que anima a Cámara y, por extensión, a "la gente del pueblo" es "un placer endemoniado, que total y felizmente ignora la clase culta que puebla la tierra conquistada por Valdivia" (Blest Gana, 1897: 117). El mestizaje explica la belicosidad de Cámara, naturaliza su conducta, le arrebata cualquier lucidez sobre el lugar que ocuparía en la épica nacional y, por simple oposición, dibuja la limpieza étnica de la "clase culta".

La belicosidad de Cámara no remite a fervor patriótico ni a código militar alguno sino que acusa las causas naturales y raciales de la obsesión popular por la violencia. Ese "placer endemoniado" por la sangre, combustible bélico de la resistencia criolla y de la épica independentista, es una amenaza latente para la hegemonía de las élites criollas. La necesidad de precisar la participación de los diversos actores en la gesta independentista permite preservar el liderazgo de las élites y asumir la natural peligrosidad de figuras híbridas que se mueven belicosas e ilegibles en los bordes del texto hegemónico nacional. Lo social está sometido a un paradigma político e histórico de base racial. Tanto así que al caracterizar a Cámara y su gente, para decirlo en los términos de Sonia Montecino, "clase y etnia serán categorías intercambiables" (1993: 15). La otredad de Cámara deriva lo social de lo racial y lo hereditario, ligando sus diferencias al orden natural. El relato no sólo

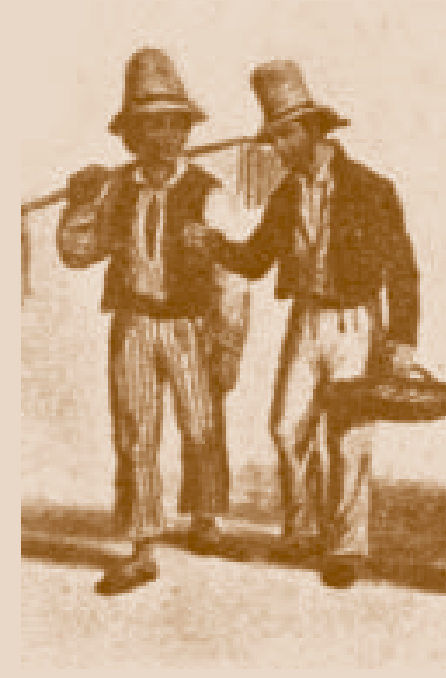




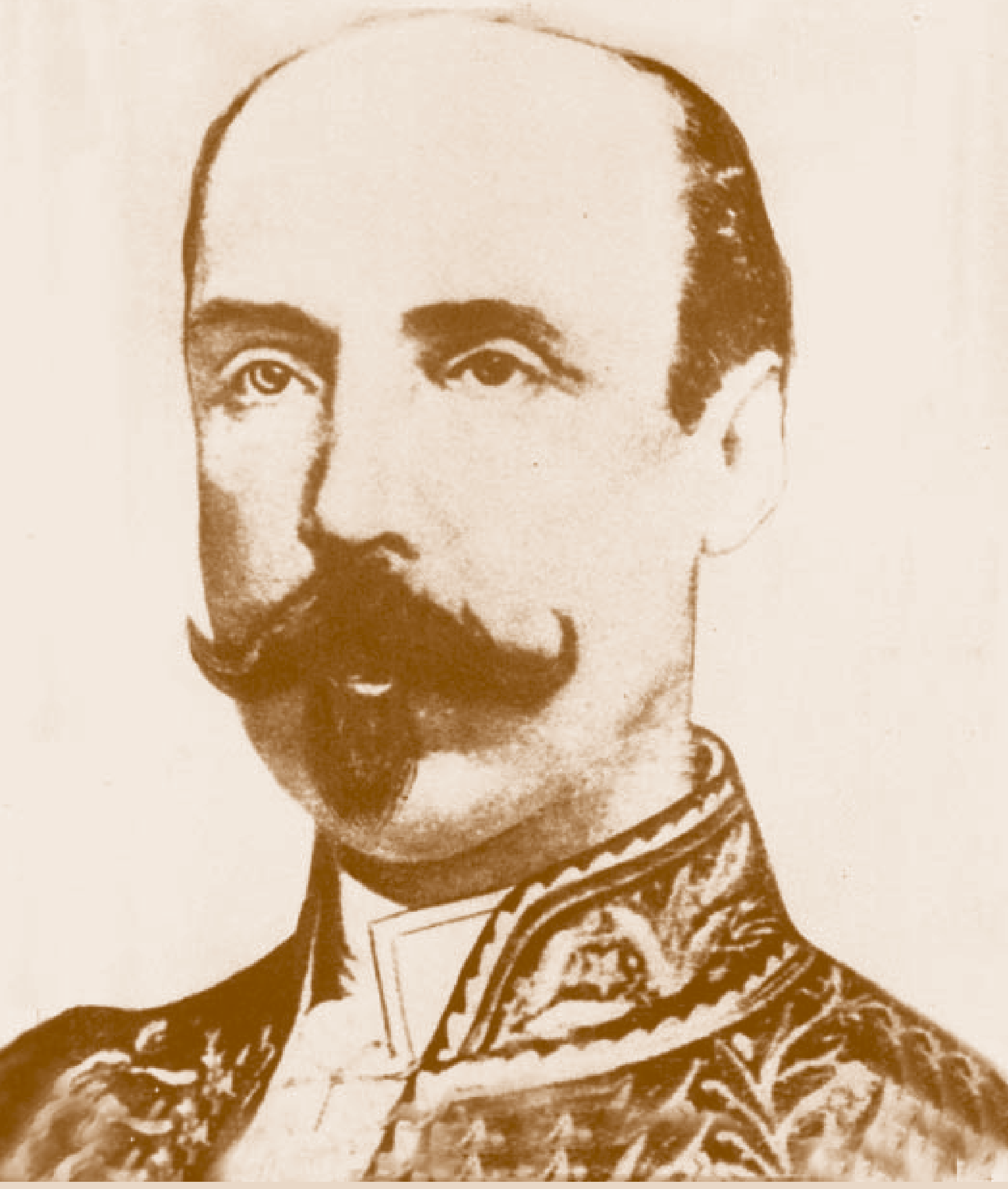

A. Blest Gana 
presume una diferencia étnica sino que formula la construcción de una diferencia social fundada sobre todo en criterios raciales. Como dice Mónica Quijada, "el movimiento hacia la homogeneización propio del nacionalismo fue desigualador por antonomasia, porque tendió a traducir en desniveles sociales la diversidad cultural y étnica" (2000: 19). Sin embargo, el habla y la figura de Cámara no remiten a un grupo étnico específico sino a una hibridez racial que liga lo árabe, lo español y lo mapuche al racializar lo popular. Es una figura abyecta cuyo placer por la violencia radica en su hibridez.

El principio del placer por la sangre, que la anima, amenaza el orden que esa misma agresividad habría ayudado a crear. En consecuencia, la natural belicosidad de Cámara sólo es políticamente funcional e históricamente productiva bajo la hegemonía de las élites. Cámara, "hijo de español plebeyo que le había legado su singular apellido, y de una huasa cuarterona de Arauco, había sentido desde su primera reyerta seria, jugando a cara o cruz, un encanto fascinador al dar su primera puñalada" (Blest Gana, 1897: 118). Cámara, por lengua, raza y origen, es un peligro latente porque "[s]in ser ingénitamente malo, con grandes dotes de corazón, [y] siendo capaz de nobles arranques de abnegación y de cariño, le gustaba la sangre" (Blest Gana, 1897: 117). Al derivar lo social de lo étnico o hacerlos sinónimos, Blest Gana sigue la noción de "pueblo" o "bajo pueblo" acuñada, según Gabriel Salazar, por las élites criollas a partir de 1830 (2000: 10). La noción traza su lugar en un orden hegemónico y fija el origen de sus patologías sociales. A Cámara, “[e]l huracán revolucionario lo encontró así preparado para empuñar el fusil y lanzarse a la contienda" y así fue "[a]listado como voluntario en el ejército que marchó al Sur a detener la invasión de Pareja” (Blest Gana, 1897: 118). Desde el sur, territorio de fronteras para el imaginario santiaguino del siglo XIX, Cámara retornó a las órdenes de su doble, el entonces capitán Robles. Este es, en el segmento que analizo, quien le ha ordenado entregar su testimonio sobre Rancagua en Talagante.

Robles y Cámara parecen unidos por amistad y jerarquía militar. De Cámara, fue "[s]u temerario arrojo y lo festivo de su carácter [lo que] le hicieron conquistarse la viva simpatía de aquel oficial fanático por la patria, para el cual el peligro tenía una fascinación irresistible" (Blest Gana, 1897: 118). Sin embargo, más allá de la atracción del peligro, el oficial tiene un código de conducta ligado al fetichismo y la iconografía militar (Blest Gana, 1897: 108). Robles es una figura paternal para el guacho vagabundo enrolado por devoción y placer por la sangre, con la que forja una relación de lealtad sujeta. Se trata de obediencias y lealtades diferentes a las que tiene Cámara con lo familiar y cotidiano. Al proponer a Cámara como mensajero entre Manuel Rodríguez y la familia Malsira, Luisa Bustos, personaje destacado, lo define como "un hombre enteramente seguro y de un arrojo temerario", 
añadiendo que "[s]e ha criado en nuestra familia y es de una fidelidad a toda prueba" (Blest Gana, 1897: 90). Sobre ese vínculo familiar y patronal, la lealtad de Cámara es buscada para encarar desafíos ligados a la hechura de la nación y la restauración del orden patriarcal de la hacienda. El rotito había nacido, precisamente, en el fundo Los Canelos, fruto de "un desliz de ña Peta" (Blest Gana, 1897: 117).

El lugar de nacimiento era "un fundo de crianza situado cerca de Melipilla", donde tempranamente la novela focalizó " $[\mathrm{u}] \mathrm{n}$ rincón de naturaleza abandonado" donde diversos insectos y alimañas "reinaban descuidados y haciéndose la implacable guerra con que tratan de exterminarse todos los seres vivientes, por esa ley inflexible de eterna destrucción, que Darwin ha venido después a llamar 'la lucha por la vida"' (Blest Gana, 1897: 37-8). Para Gotschlich, los dueños del fundo, los Malsira, son "una expresión viva de la estratificación nuclear de la familia aristocrática, proyectada como conciencia del criollo y condensadora de ciertos atributos de nacionalidad" (1992: 48). La lealtad de Cámara a los Malsira media su relación con los eventos políticos en los que participa y liga su origen a los espacios domésticos del orden patricio. La singularidad y la diferencia que determinan la otredad de Cámara permiten subrayar que sus lealtades están sujetas al orden doméstico del fundo. Su obediencia, sin embargo, opera bajo mecanismos disciplinarios diferentes. Es el tránsito y protagonismo que logra Cámara entre ambos espacios el que lo dota de un signo transitivo, mediador, conector.

En un episodio donde Cámara, tras una lucha cuerpo a cuerpo, se dispone a matar a un soldado realista que se ha rendido, Robles lo detiene y le grita que “¡a enemigo en el suelo se le perdona!” (Blest Gana, 1897: 150). Luego de escuchar la orden, indica la novela, "Cámara miró al Mayor casi con odio; vaciló un momento como si allá, en lo recóndito de su cerebro encendido, se levantara una protesta de rebelión, una queja amarguísima contra la autoridad del jefe, cuya generosidad no comprendía" (Blest Gana, 1897: 150). Acto seguido y "bajando la frente, [Cámara] se retiró con paso tardo y con la penosa resignación de un perro, al que el amo impone su voluntad, arrancándole la presa con que empezaba a saborearse" (Blest Gana, 1897: 150). El principio del placer y el encanto por la sangre es doblegado por la jerarquía y la sumisión al jefe. La lealtad doméstica es traducida al ámbito público mediante el disciplinamiento militar y la figura subalterna es homologada a la sumisión del perro. La analogía se repite, en otro momento, al precisarse que "Cámara correspondía al afecto paternal de su jefe, con la abnegación inteligente del perro al que han dado a guardar un niño" (Blest Gana, 1897: 120). Bajo la paterna conducción de un oficial intermedio leal al relato patriótico y a la iconografía militar, la violencia natural de Cámara se transforma en el combustible popular de la épica nacional.

El sitio que delinea la peligrosidad de un híbrido es tan natural durante la Reconquista como marginal a fines del siglo XIX. Cámara contribuye a la 
hegemonía de las élites criollas y es un factor decisivo en la factura de un imaginario popular y bélico tras su domesticación. La novela traslada la metafórica presencia de Cámara en el eje del discurso sobre la Reconquista a una metonímica reflexión sobre lo subalterno y popular a fines del siglo XIX. En un esfuerzo por caracterizar la subalternidad, Horacio Legrás señala que la diferencia ontológica de la otredad no es reductible a la diferencia relacional del subalterno (2000: 87). Sin embargo, en la novela, la otredad de Cámara permite cartografiar socialmente su lugar al desplazar lo relacional a lo ontológico tras su naturalización. Lo social no admite sino una lectura sujeta a los criterios y sustantividades de la naturaleza. El lugar de Cámara, de su subalternidad, diagrama el sitio de lo popular en este relato que explora la emergencia de una nacionalidad. Su traducción a signo de lo popular le otorga a Cámara el mismo protagonismo que lo saca del panteón fundacional de la élite criolla. Blest Gana señala que tras el desastre de Rancagua, los jefes militares derrotados habían sido "agrupados como una aureola de constelaciones luminosas en torno del gran nombre de O'Higgins", donde "habían llegado a encarnar el culto del pueblo por esa deidad, la Patria, que vive de sacrificios, como los dioses de la idolatría" (Blest Gana, 1897: 3). Desde su muda subalternidad, Cámara testimonia ese culto a los jefes de la derrota pero, asimismo, le permite a la novela esbozar la crisis de liderazgo que habría hundido la Patria Vieja.

En su testimonio, Cámara indica que habría burlado el cerco de Rancagua para llevarle a José Miguel Carrera un mensaje de Bernardo O’Higgins y que habría retornado con una promesa de apoyo (Blest Gana, 1897: 114). El padre de Cámara había muerto a las órdenes de Carrera cuando se estrelló contra el sitio de Chillán en 1813 (Blest Gana, 1897: 87). La misión de llevarle el mensaje al entonces General en Jefe le había sido encomendada tras una recomendación hecha por el mayor Robles a O'Higgins. Cámara permite llenar un vacío en el imaginario historiográfico. Cámara no es sólo un informante estratégico sino que el protagonista de una fisura narrativa sobre el texto de lo que Dipesh Chakravarty llamaría un pasado subalterno (2000: 101). La brecha o crisis al interior del liderazgo criollo halla en la subalternidad el soporte de su articulación. Desde ese pasado, donde las élites y los grupos subalternos responden a una misma empresa histórica, Cámara testimonia el fracaso del liderazgo criollo que hundió la Patria Vieja. Ese fracaso no podría narrarse orgánicamente ligado al relato hegemónico. El habla de Cámara, sin embargo, queda fuera de la escritura y su aporte a la epopeya fundacional se reduce al escenario bélico. Allí, es el simulacro de lo popular que articula la ficción histórica de Blest Gana. En tal sentido y a pesar de la crítica de Carlos Reynoso al término "articulación", por la imprecisión y elasticidad del concepto, creo que define el sitio de Cámara en la novela (2000: 103). Cámara articula ámbitos irreductibles en el relato novelesco que despliega el ejercicio crítico de Blest Gana sobre la historiografía.

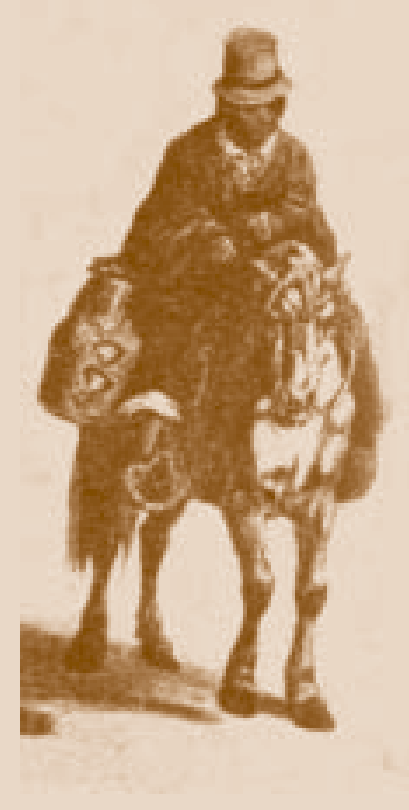




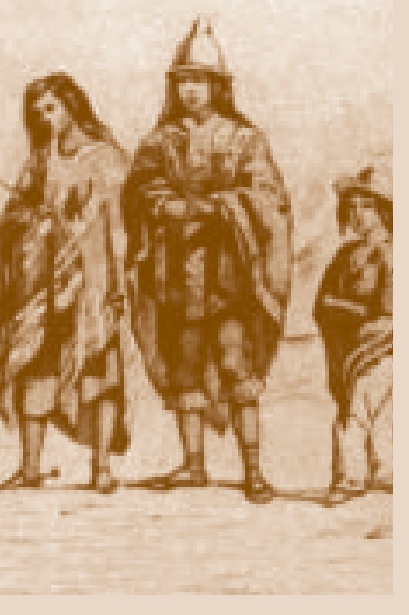

Dicha articulación u operatividad sintáctica al interior del texto nacional permite una dialéctica de integración, traducción y anulación. No se trata de una desviación narrativa para contar la misma historia bajo una variación dialectal sino que de hacer de lo subalterno la sutura de una instalación hegemónica.

Cámara emerge, por lo tanto, como la fisura que disloca el relato hegemónico de una nacionalidad decimonónica en crisis a fines del siglo XIX en el instante mismo en que testimonia su hegemonía. Esto hace de Cámara un tropo subalterno, cooptado por el texto y permite alejarse de la lectura mimética que hace de su singularidad lo popular o lo chileno mismo. Es lo que llevó a Gotschlich a decir que es el "simbólico representante del roto chileno" y a Mireya Camurati a indicar que era "el prototipo del roto chileno (Gotschlich, 1998: 11; Camurati, 1974: 98). Es, también, el énfasis de Bélgica Watts por ver en la obra de Blest Gana el realista "perfil del chileno" (1994: 614). Giuseppe Bellini llega a asegurar, incluso, que con Cámara, "la historia se nos presenta como a través de una lupa, la visión popular, frente a un público rural atento, silencioso y de escasas reacciones, más sensible a la suerte de los caballos que a la de los hombres" (1998: 17). Más allá de esos códigos miméticos, Cámara testimonia la heroicidad de las élites criollas mediante su propio, corregido, ficcional y subalterno protagonismo. Ese testimonio ordena la visión de la que hasta hoy sigue considerándose "la principal obra de toda esta novelística" histórica en Chile, según Evelio Echevarría (1992: 647). Esta acota y define la ficción de lo popular al interior de un relato hegemónico tras su legitimación.

Hay, sin embargo, otro aspecto de esta caracterización de Cámara en la novela. Cabe recordar que en un diálogo entre Luisa Bustos y Manuel Rodríguez, Cámara es elegido como vínculo entre la familia Malsira, eje de la ficción histórica de la novela, y Manuel Rodríguez, eje de la narrativa historiográfica del periodo. En otro momento, Cámara surge desde la ficción para testimoniar el último contacto entre O'Higgins y Carrera antes de la caída de la Patria Vieja. El protagonismo de las elites criollas hace de Cámara el sitio donde la visión histórica de Blest Gana articula la totalidad interpretativa de su novela. No sólo las élites y su instalación hegemónica se resuelven sobre él sino que también descansa la factura general del relato. La textura narrativa de la ficción histórica de Blest Gana apela a un afuera que sutura una fractura narrativa. Alberto Moreiras dice que el género testimonial puso en la escena transnacional una identidad política latinoamericana ligada a la posibilidad de articular nuevos movimientos sociales (2001:214). En un sentido comparable, el testimonio novelesco y la presencia de Cámara en la ficción histórica de Blest Gana responden a un silencio que sutura la fragilidad de la hegemonía criolla finisecular en el momento de su despliegue. Dicha hegemonía, no sólo política sino que narrativa e histórica, tiene 
su juntura en un lugar externo a ella; su articulación, a partir de una ventriloquia historiográfica, es su prueba. Por otra parte, la escasa legibilidad del habla de Cámara y su necesaria corrección no sólo coopta ese discurso sino que alude a una subalterna fuente de legitimidad poco confiable para la narrativa hegemónica que sostiene la nacionalidad. Advierte, en este caso, de un peligro, en cuyo caso la novela histórica de Blest Gana no es la lukacsiana y concreta prehistoria del presente sino la prehistoria del futuro (Lukács, 1983: 296). La sutura que narra, desde la otredad, la semilla episódica de la nacionalidad responde a un relato que fetichiza cualquiera de sus posibles gestos disruptivos.

La novela previene o controla la presencia desestabilizadora de Cámara, su habla y testimonio, de los suyos, mediante su sujeción a un orden discursivo cuya legitimidad no apela a su representatividad sino a su legibilidad. Esa legibilidad está vinculada a una cartografía política de lo popular capaz de redefinir su lugar de cara al nuevo siglo. En tal sentido, la novela es también una reflexión acerca de la solidez, en un relato de transición, de una hegemonía que, según afirma Alfredo Jocelyn-Holt, se vio apenas alterada por la crisis política que habría desembocado en la independencia (1992: 164). Si la Reconquista forjó lo que Salazar ha llamado "una entidad socioespiritual congregada por la existencia de un sentimiento de homogeneización interna: el de patria", los nuevos procesos sociales e históricos la estarían mutando a fines del siglo XIX (2000: 11). Según Camurati, la novela "alude sin mayores detalles a la discordia entre los patriotas, y a las rivalidades entre los hermanos Carrera y O’Higgins" (1974: 95). Sin embargo, creo que no importa que Cámara narre los sucesos de Rancagua "desde su punto de vista de soldado completamente ignorante de la estructura técnico-militar" (Camurati, 1974: 95). Lejos de atribuirle una homogénea y transparente conciencia a la élite, la novela de Blest Gana y el testimonio de Cámara subrayan la persistencia de sus contradictoriedades.

En la novela de Blest Gana, la chilenidad opera entre su condición de narrativa de emancipación y su concreción como relato de orden. Sin embargo, como precisa Ernesto Laclau, un discurso de emancipación requiere instalar una otredad frontalmente diferente con cual se propone romper, si ese discurso es radicalmente diferente al orden dado (1996: 4). En este sentido, los realistas que constituyen la otredad de los patriotas en el contexto de la Reconquista no son la referencia de la mirada decimonónica finisecular del episodio. Frente a ésta, el violento placer de Cámara se torna sospechoso. Está claro, como dice Epifanio San Juan leyendo a Gramsci, que lo subalterno no es un dato empírico sino un dispositivo teórico para abordar la relación entre orden y cambio en una sociedad (1998: 86-7). Cámara es, precisamente, un dispositivo que opera, al menos, en dos niveles. Por un lado, sutura la construcción narrativa de una nacionalidad proyectada como

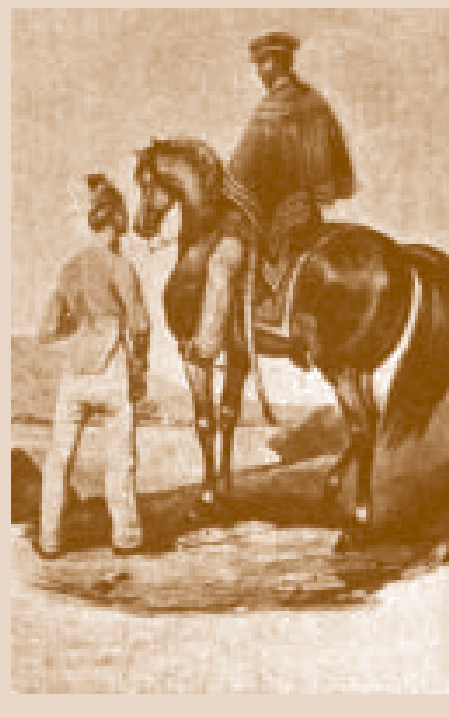




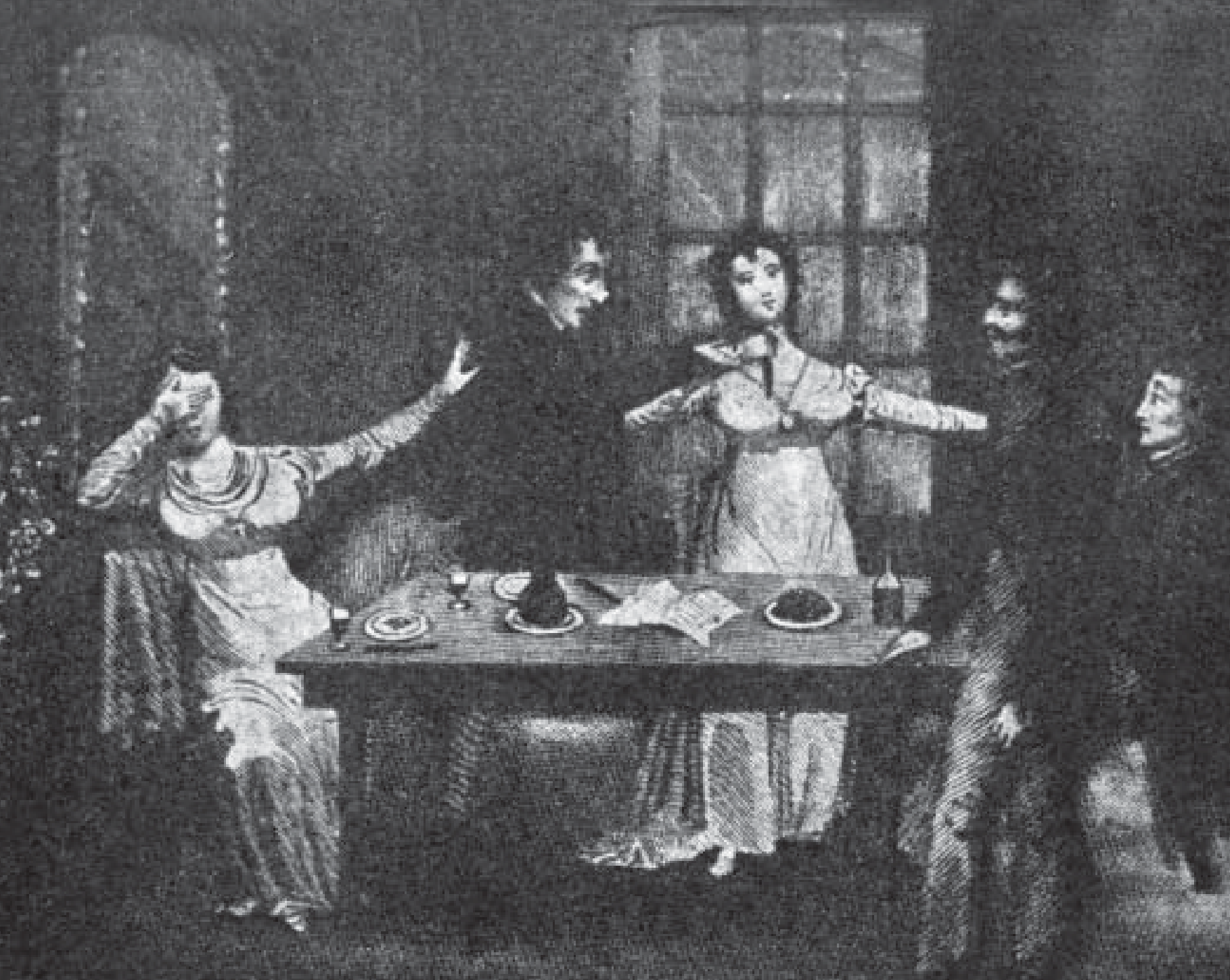


relato de emancipación que testimonia la hegemonía y liderazgo de las élites criollas. Por el otro, Cámara es el habla corregida que hace de la subalternidad el signo legible de lo popular en una narrativa de chilenidad postulada como relato de orden a fines del siglo XIX. Esto permite poner de cabeza la fórmula de Gareth Williams y señalar que es a través de lo popular que se torna legible lo subalterno (2002: 11). Esa legibilidad permite diagnosticar la fragilidad de la hegemonía de las élites criollas a partir del relato episódico que instaló y legitimó su despliegue, no al revés.

El de Cámara es un testimonio ligado tanto a la aurora como al futuro de un relato hegemónico de nacionalidad. Ernesto Laclau y Chantal Mouffe señalan que la hegemonía remite a la ausencia de una totalidad y sobre cuyo vacío operan diversos intentos políticos orientados a superar ese oquerón original (1985: 7). Sobre ese vacío, Cámara narra la derrota inaugural que sostiene la nacionalidad y la ficción histórica mismas. Lo hace sin espacio para las "estrategias de fuga y resistencia" o de "burla y contestación" que Julio Ramos ve en la lengua del subalterno (1993: 16). Ni siquiera hay lugar para una identidad estratégica, como la debatida por Spivak, que le permitiera incidir sobre la narrativa que lo coopta (Spivak, 1993: 4). Sobre esa totalidad narrativa, diría Raúl Silva Castro, la relación blestganiana despliega un juego de ficción y erudición en diálogo con las narrativas historiográficas (1934: 79). Esto, sin embargo, hace posible ubicar a Cámara no sólo como mecanismo de articulación del liderazgo criollo, de sutura de su hegemonía y punto de partida de la ficción histórica.

Cámara, cuya historia arranca a pie luego de morir el caballo con el que había escapado, junto a Robles, de Rancagua, cubre otra ausencia. Como indica la novela, los "heroicos defensores de la plaza" de Rancagua, no sólo habían conseguido "con su arrojo convertir una derrota en una de las más brillantes páginas de la historia chilena" sino que, sobre todo, "habían tramontado los Andes, dejando la patria enlutada y los hogares en lágrimas" (Blest Gana, 1897: 3). Sobre la fuga y el vacío de los héroes militares, del liderazgo mismo que hacía posible la articulación de una comunidad y de la Patria Vieja pulverizada, surge la resistencia, la espera y, sobre todo, el discurso del retorno de los salvadores de la patria. La emergencia subalterna de Cámara no interrumpe sino que media ese proceso, lo suturan sus acciones y testimonio. La transición entre uno y otro momento remite no sólo a su relato y su subalterno protagonismo sino que, también, sugiere la necesidad de su eliminación y disciplinamiento tras el retorno de los héroes.

\section{REFERENCIAS}

Balibar, Etiene. 1995. “Ambiguous Universality”. Differences 7.1: 48-74. . 1997. "La forme nation: histoire et idéologie". Race, nation, classe. Les 
identités ambiguës. Ed. Balibar and Wallerstein. Paris: La Découverte, 11743.

Bellini, Giuseppe. 1988. “Alberto Blest Gana historiador de Chile”. Rassegna Iberistica 31: 3-17.

Beverley, John. 1999. Subalternity and Representation. Durham: Duke UP.

Bhabha, Homi. 1994. The Location of Culture. London: Routledge.

Blest Gana, Alberto. 1897. D urantela Reconquista. Vol 1. París: Garnier Hermanos.

Butler, Judith. 2000. "Restaging the Universal”. Contingency, Hegemony, Universality. Judith Butler, Ernesto Laclau and Slavoj Zizek. London: Verso, 11-43.

Camurati, Mireya. 1974. "Blest Gana, Lukacs, y la novela histórica". Cuadernos Americanos 197: 88-99.

Chakrabarty, Dipesh. 2000. Provincializing Europe. Princeton: Princeton UP.

Echevarría, Evelio. 1992. "La novela histórica de Chile: Deslinde y bibliografía, 1852-1990”. Revista Interamericana de Bibliografía / Inter-American Review of Bibliography 42.4: 643-50.

Escudero, Alfonso M. 1945. “Prólogo”. El loco Estero. Buenos Aires: Ediciones Jackson, VII-LVIII.

Fuenzalida Grandón, A. 1921. Alberto Blest Gana y su arte de novelar. Santiago de Chile: Editorial Universitaria.

Genette, Gerard. 1980. Narrative Discourse. Ithaca: Cornell University Press.

González Echevarría, Roberto. 1990. M yth and Archive. Cambridge: Cambridge UP.

Gotschlich, Guillermo. 1992. El realismo en la novelística de Blest Gana. Santiago de Chile: RIL. . 1998. "Cien años de Durantela reconquista”. Revista Chilena de Literatura 52: 5-15.

Hernández, Roberto. 1929. El roto chileno. Valparaíso: Imprenta San Rafael. Jitrik, Noé. 1986. "De la historia a la escritura". The Historical Novel in Latin America. Ed. Daniel Balderston. Gaithersburg: Hispamérica, 13-29.

Jocelyn-Holt, Alfredo. 1992. La independencia deChile. Madrid: Editorial Mapfre. Laclau, Ernesto. 1996. Emancipation(s). London: Verso.

Laclau, Ernesto \& Chantal, Mouffe. 1985. Hegemony and Socialist Strategy. London: Verso.

Legrás, Horacio. 2000. "Subalternity and Negativity”. Dispositio N 22.47: 83102.

León, Leonardo. 2002. "Reclutas forzados y desertores de la patria. El bajo pueblo chileno en la guerra de la independencia". H istoria 35: 251-97.

Lukács, Gyorgy. 1983. The H istorical N ovel. Lincoln: U. of Nebraska P. Montecino, Sonia. 1993. Sangres cruzadas. Santiago de Chile: Sernam. Moreiras, Alberto. 1999. Tercer espacio. Santiago de Chile: Lom. . 2001. The Exhaustion of Difference. Durham: Duke UP.

Quijada, Mónica et al. 2000. H omogeneidad y nación. Madrid: CSIC, 15-55.

Ramos, Julio. 1993. "El don del habla". Casa delas Américas 34.193: 13-25.

Reynoso, Carlos. 2000. A pogeo y decadencia delos estudios culturales. Barcelona: Editorial Gedisa. 
Rodríguez-Arenas, Flor María. 1993. Hacia la novela. Bogotá: Códice.

Rossner, Michael. 1999. "De la utopía histórica a la historia utópica”. La novela latinoamericana entre historia y utopía. Ed. Sonja M. Steckbauer. Eichstatt: Zentralinstitut fur Lateinamerika-Studien, 68-50.

Salazar, Gabriel. 2000. Labradores, peonesy proletarios. Santiago de Chile: Lom. San Juan, Epifanio. 1998. Beyond Postcolonial Theory. New York: St. Martin's Press.

Silva Castro, Raúl. 1934. Blest Gana y su novela D urantela Reconquista. Santiago de Chile: Imprenta Universitaria. . 1960. H istoria crítica de la novela chilena. Madrid: Cultura.

Sklodowska, Elzbieta. 1992. Testimonio hispanoamericano. New York: Peter Lang. . 1996. "Spanish American Testimonial Novel: Some Afterthoughts".

The Real Thing. Ed. George M. Gugelberger. Durham: Duke UP, 84-100.

Sommer, Doris. 1999. Proceed with Caution. Cambridge: Harvard UP.

Spivak, Gayatri. 1993. Outside in the Teaching M achine. London: Routledge. . 1994. "Can the Subaltern Speak?" Colonial Discourse and Post-Colo-

nial Theory. Ed. Patrick Williams and Laura Chrisman. New York: Columbia UP, 66-111. . 1999. A Critique of Postcolonial Reason. Cambridge: Harvard UP.

Torres Rioseco, Arturo. 1962. "La novela chilena contemporánea”.J ournal of InterAmerican Studies 4.4: 503-16.

Watts, Bélgica. 1994. "Algunos rasgos del chileno en obras de Alberto Blest Gana (1830-1920)". Romance Languages Annual 6: 614-8.

White, Hayden. 1975. M etahistory. Baltimore: The John Hopkins UP.

Williams, Gareth. 2002. The Other Side of the Popular. Durham: Duke UP.

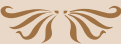

